CrossMark

$\leftarrow$ click for updates

Cite this: Dalton Trans., 2017, 46, 3805

Received 21st December 2016, Accepted 13th February 2017

DOI: $10.1039 / \mathrm{c} 6 \mathrm{dt} 04811 \mathrm{k}$

rsc.li/dalton

\section{Axially chiral racemic half-sandwich nickel(II) complexes by ring-closing metathesis $\uparrow$}

\author{
Włodzimierz Buchowicz, ${ }^{\star a}$ Łukasz Banach, ${ }^{a}$ Radosław Kamiński ${ }^{b}$ and \\ Piotr Buchalskia
}

\begin{abstract}
A remarkable nickelacycle has been synthesised via olefin metathesis of the $\alpha, \omega$-diene complex $\left[\mathrm{Ni}\left(\eta^{5}-\mathrm{C}_{5} \mathrm{H}_{4} \mathrm{R}\right)(\mathrm{Br})(\mathrm{NHC})\right](\mathrm{R}=$ $\mathrm{C}\left(\mathrm{CH}_{3}\right)_{2} \mathrm{CH}_{2} \mathrm{CH}=\mathrm{CH}_{2}, \quad \mathrm{NHC}=$ 1-(6-hexenyl)-3-(2,4,6-trimethylphenyl)-imidazol-2-ylidene). Single-crystal X-ray analysis reveals a helical shape of the molecule and stretching of some interatomic distances in the $\mathrm{Ni}$ (II) coordination sphere. The $\mathrm{Cp}-\mathrm{NHC}$ tethered complex shows catalytic activity resembling that of the parent complexes.
\end{abstract}

Asymmetric catalysis with the chiral derivatives of the ubiquitous cyclopentadienyl (Cp) ligand remains an undeveloped area of research. ${ }^{1}$ The diamagnetic complexes $[\mathrm{Ni}(\mathrm{Cp})(\mathrm{X})$ $(\mathrm{NHC})](\mathrm{X}=\mathrm{Cl}, \mathrm{Br}, \mathrm{I}$, alkyl; NHC = N-heterocyclic carbene), initially discovered by Abernethy et al. ${ }^{2}$ have found numerous applications as pre-catalysts ${ }^{3}$ or robust substrates in the synthesis of novel species. ${ }^{4}$ We have presumed that a convenient synthesis of a Cp-NHC tethered nickel complex of this type could open up access to novel axially chiral molecular frameworks with applications in catalysis, chiral recognition, or separation.

Transition-metal complexes bearing chelating Cp-NHC ligands are usually prepared from bidentate pro-ligands and suitable metal sources (Scheme 1, path i). ${ }^{5}$ Despite the considerable variety of the so far reported complexes $[\mathrm{Ni}(\mathrm{Cp})(\mathrm{X})$ (NHC)], to the best of our knowledge, few examples of closely related indenyl-NHC Ni(II) complexes ${ }^{6}$ and $\mathrm{C}_{5} \mathrm{Me}_{4}-\mathrm{NHC}$ congeners ${ }^{7}$ have been synthesised by this route. We hypothesized that a $\mathrm{Cp}$-NHC tether could be readily formed via ring-closing metathesis (RCM) $)^{8,9}$ in bis-alkenyl complexes (Scheme 1, path ii). Herein, we explore this novel route to axially chiral halfsandwich $\mathrm{Ni}$ (II) complexes.

\footnotetext{
${ }^{a}$ Faculty of Chemistry, Warsaw University of Technology, Noakowskiego 3, o0-664 Warsaw, Poland. E-mail: wbuch@ch.pw.edu.pl; Fax: +48 22234 5462; Tel: +48222345150

${ }^{b}$ Department of Chemistry, University of Warsaw, Żwirki $i$ Wigury 101, 02-089 Warsaw, Poland

$\dagger$ Electronic supplementary information (ESI) available: Additional experimental details and figures. CCDC 1504275 and 1504276. For ESI and crystallographic data in CIF or other electronic format see DOI: 10.1039/c6dt04811k
}

(a)

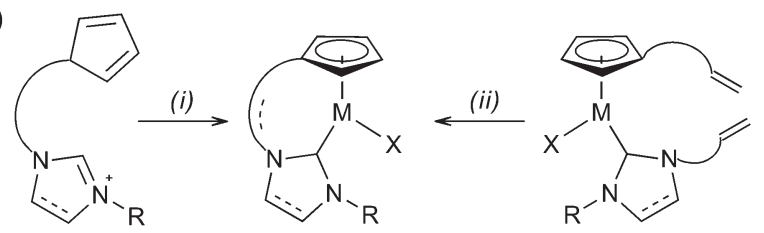

(b)
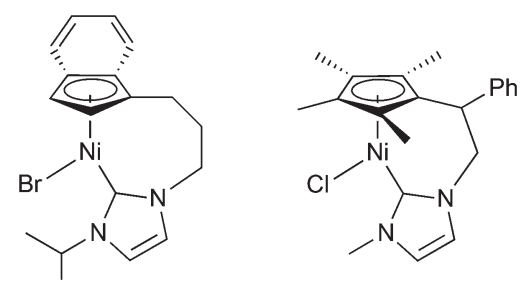

Scheme 1 (a) General synthetic approaches to Cp-NHC complexes: (i) double deprotonation, then $\mathrm{MX}_{2}$ (ii) suitable metathesis catalyst, this work; (b) examples of $\mathrm{Ni}\left(\right.$ II) complexes prepared by route i. ${ }^{6,7}$

Plausible RCM substrates, the $\alpha, \omega$-diene complexes $\mathbf{1}$ and 2, were prepared according to the standard procedure ${ }^{2}$ from the appropriate imidazolium salts and 1,1'-bis-(alkenyl)nickelocene (Scheme S1†).

Based on the precedence of complexes prepared from bidentate pro-ligands that are 6- or 7-membered metalacycles (Scheme 1b), we expected that complex 1 would readily undergo RCM to form a 10-membered ring. Thus, 1 was treated with $6 \mathrm{~mol} \%$ of $\left[\mathrm{Ru}(=\mathrm{CHPh}) \mathrm{Cl}_{2}\left(\mathrm{PCy}_{3}\right)(\mathrm{SIMes})\right]^{10}$ under dilute conditions $([\mathrm{Ni}]=0.01 \mathrm{M})$ in refluxing toluene or $\mathrm{CH}_{2} \mathrm{Cl}_{2}$ (Scheme 2). Surprisingly, RCM in complex 1 proved to be ineffective. ${ }^{11}$ The presence of the expected product 3 could be determined only by means of mass spectrometry $\left([\mathbf{M}]^{+}\right.$at $\mathrm{m} / \mathrm{z}$ $\left.496\left({ }^{58} \mathrm{Ni},{ }^{79} \mathrm{Br}\right)\right)$.

Fortunately, RCM in complex 2 catalysed by $[\mathrm{Ru}(=\mathrm{CHPh})$ $\left.\mathrm{Cl}_{2}\left(\mathrm{PCy}_{3}\right)(\mathrm{SIMes})\right]$ proceeded smoothly in hot toluene to yield the 12-membered nickelacycle 4 . The formation of the $\mathrm{Cp}$ NHC tether renders all proton and carbon signals non-equivalent in the NMR spectra of $\mathbf{4}$, e.g. the Cp protons are represented by four multiplets at $\delta 4.96,4.86,4.61$, and $4.02 \mathrm{ppm}$. 

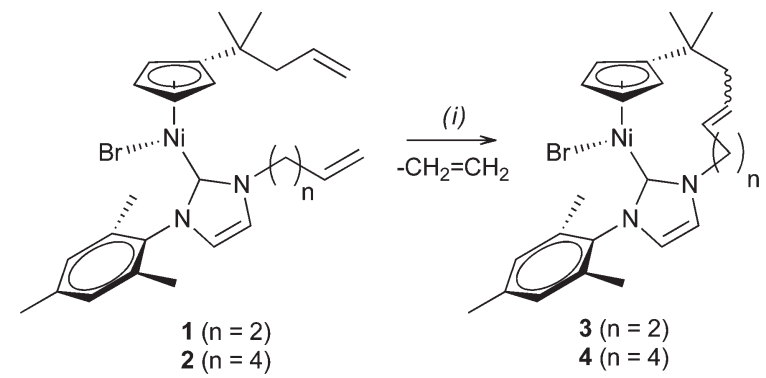

Scheme 2 RCM in complexes 1 and 2: (i) $\left[\mathrm{Ru}(=\mathrm{CHPh}) \mathrm{Cl}_{2}\left(\mathrm{PCy}_{3}\right)(\mathrm{SIMes})\right]$, $6 \mathrm{~mol} \%$, toluene or $\mathrm{CH}_{2} \mathrm{Cl}_{2}$, reflux.

Moreover, a detailed inspection of the ${ }^{1} \mathrm{H}$ and ${ }^{13} \mathrm{C}$ NMR spectra reveals the presence of two isomeric products. This finding is most clearly evidenced by two $\mathrm{Ni}^{-} \mathrm{C}_{\text {carbene }}$ resonances at $\delta 165.3 \mathrm{ppm}$ (major) and $165.8 \mathrm{ppm}$ (minor). We identify these two products as, respectively, $E$ and $Z$ isomers of the $\mathrm{C}=\mathrm{C}$ double bond formed in the metathesis reaction (see below). The two isomers were obtained in a ca. $10: 3$ ratio. $^{12}$

The X-ray diffraction studies allowed us to derive the crystal structures of complexes $\mathbf{1}$ and 4. Attempts to obtain a sufficient quality crystal structure of complex 2 were moderately successful (Fig. S1†). Nevertheless, the qualitative confirmation of the molecular structure of 2 shows its general similarity to that of $\mathbf{1}$. Consequently, a direct comparison of $\mathbf{1}$ and 4 allows one to gain structural insights into the differences and similarities of complexes before and after the intramolecular metathesis reaction.

Compounds 1 and 4 crystallise in the monoclinic $P 2_{1} / c$ and triclinic $P \overline{1}$ space groups, respectively. In both cases only one molecule is present in the asymmetric unit (Fig. 1). As both crystals are centrosymmetric, two enantiomers of each molecule are present in the analysed crystal structures. However, whereas in complex 1 rotation along the Ni1-C16 bond is possible, in $\mathbf{4}$ it is hindered due to the presence of the macrocyclic ring. This makes the molecules of $\mathbf{4}$ axially chiral, which has been confirmed in solution by NMR (Fig. 3).

We have found a small fraction of the $Z$ isomer (ca. 2-3\%) in the crystal of 4 , which is consistent with the NMR spectra. The olefin C10 and C11 atoms of the $Z$ isomer are quite well visible on the residual density plot (Fig. S2†). Even though the full refinement of both isomers was not possible, it appears that the geometry of the $\mathrm{C}=\mathrm{C}$ double bond has no significant effect on the overall shape of the molecule. ${ }^{13}$

The coordination geometry at the nickel centre is comparable in both cases (Fig. 2). The most significant differences occur for the NHC ligand, which is oriented in the solid state in complex $\mathbf{1}$ in the opposite direction than in $\mathbf{4}$, as evidenced by the Br1-Ni1-C16-N2 torsion angles of $-112.6(2)^{\circ}$ and $114.5(2)^{\circ}$ for 1 and 4 , respectively. This suggests that 1 must adopt the less favourable conformation to facilitate the intramolecular metathesis.

The formation of the macrocyclic ring also induces considerable distortions in the overall ligand arrangement. The (a)

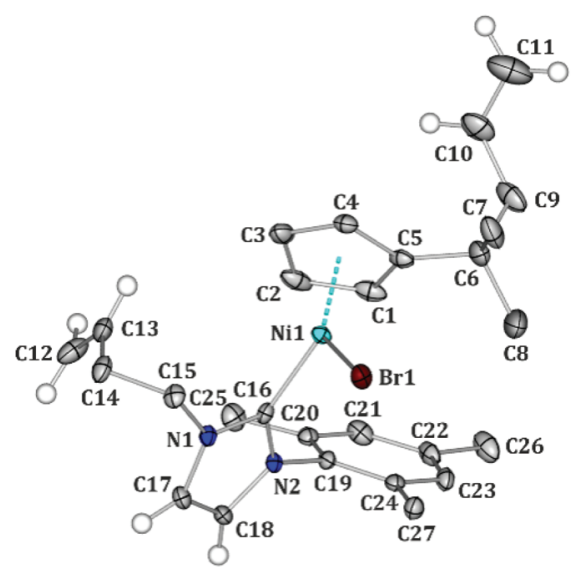

(b)

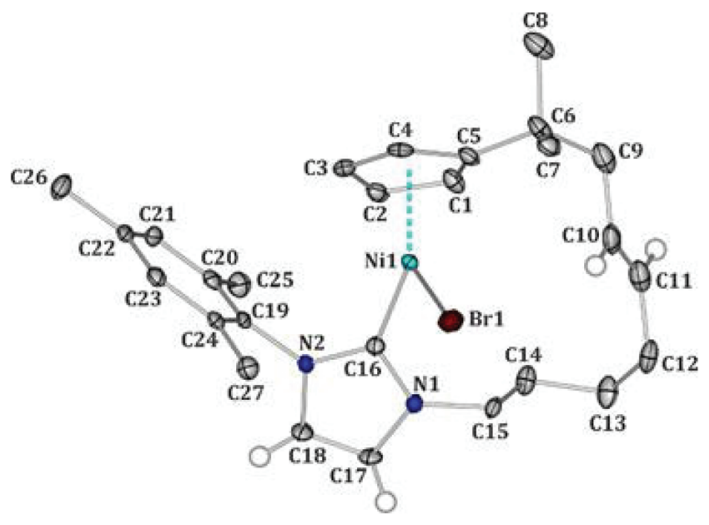

Fig. 1 Molecular structures of complexes 1 (a) and 4 ( $E$ isomer) (b). Note that in 4 the $\mathrm{C} 10-\mathrm{C} 11(1.341(5) \AA)$ bond is the double bond with $E$ configuration. Atomic thermal motion is represented as ellipsoids (50\% probability level), and some hydrogen atoms are removed for clarity.

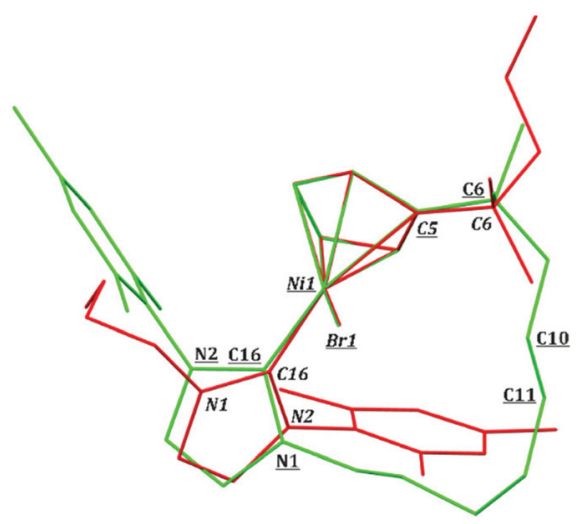

Fig. 2 Overlay of 1 (red, labels in italics) and 4 (green, labels underlined).

large ring tends to push slightly the Cp and NHC ligands away. This is most clearly demonstrated by comparing the C16-Ni1$\mathrm{Cp}_{\mathrm{cg}}$ angles $\left(131.89(8)^{\circ}\right.$ for $\mathbf{1}$ and $132.14(8)^{\circ}$ for $\mathbf{4} ; \mathrm{Cp}_{\mathrm{cg}}=\mathrm{Cp}$ ring centre of gravity). Moreover, the average Ni1- $\mathrm{C}_{\mathrm{Cp}}$ bond lengths are approximately $0.02 \AA$ larger for $4(2.157 \AA$ on average) than for $\mathbf{1}(2.140 \AA$ on average) with the Ni1-C5 bond 
being the most significantly elongated (2.203(2) A for 1 compared to 2.252(3) $\AA$ for 4). The same trend is observed for the Ni1-C16 bonds (1.877(2) A in 1 and 1.884(3) $\AA$ in 4).

In order to probe the chirality of complex 4 in solution, its NMR spectra in the presence of an NMR chiral chemical shift reagent $\left((R)-(-)-1\right.$-(9-anthryl)-2,2,2-trifluoroethanol) ${ }^{14}$ (5) were recorded (Fig. 3). Doubling of the signals due to the formation of two diastereoisomers was clearly observed for the $-\mathrm{NCH}_{2}$ multiplet at $\delta 3.43 \mathrm{ppm}$, singlet of the $o-\mathrm{CH}_{3}$ group at $\delta 2.74 \mathrm{ppm}$ ( $E$ isomer), and singlet of the $\mathrm{C}_{5} \mathrm{H}_{4} \mathrm{C}\left(\mathrm{CH}_{3}\right)_{2}$ group $\delta 1.26 \mathrm{ppm}$. This observation suggests that the chiral structure of 4 is also stable in this solution. ${ }^{15}$ Moreover, we conclude that the bromine ligand in $\mathbf{4}$ is the preferred site of its interaction with the polar reagent.

The catalytic activity of racemic 4 was tested in three $\mathrm{C}-\mathrm{C}$ bond formation reactions (Table S1 $\uparrow$ ). In the case of Suzuki coupling, the activity and selectivity to the desired cross-coupling product was comparable to those of the parent $[\mathrm{Ni}(\mathrm{Cp})(\mathrm{X})$ (NHC)] complexes (entry no. 1). Polymerization of styrene in the presence of $\mathbf{4}$ and methylalumoxane (MAO) yielded the expected atactic polystyrene (entries no. 2 and 3). Complex 4 with methyl methacrylate and MAO showed moderate activity at $50{ }^{\circ} \mathrm{C}$ (entry no. 4) and almost no activity at $20^{\circ} \mathrm{C}$ (entry no. 5).

In summary, we have shown that a Cp-NHC tether can be readily formed via olefin metathesis in the $\mathrm{Ni}$ (II) coordination sphere. The length of the alkenyl substituents as well as the dynamics of the system in solution are both the key factors for determining the propensity of the intramolecular reaction. The helical shape of $\mathbf{4}$ opens up prospects for its applications in asymmetric catalysis after the resolution of enantiomers.

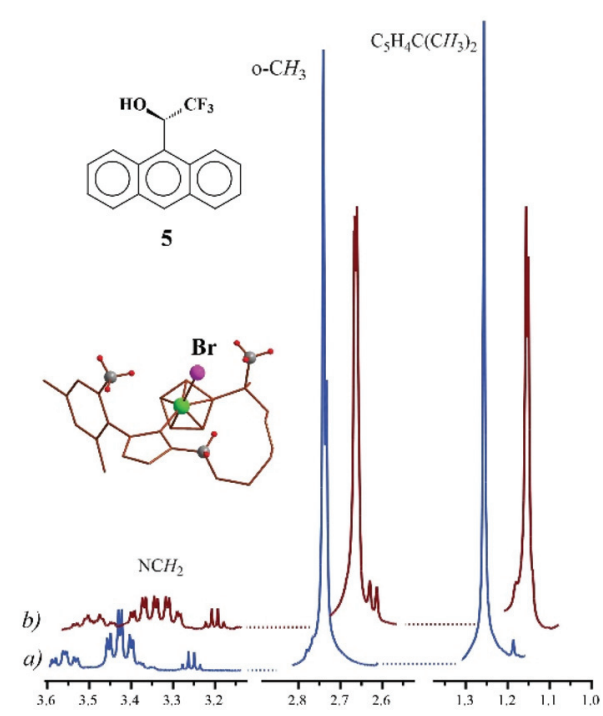

Fig. 3 (a) Selected sections of the ${ }^{1} H$ NMR $\left(500 \mathrm{MHz}, \mathrm{C}_{6} \mathrm{D}_{6}\right)$ spectrum of complex 4 ( $E$ and $Z$ isomers), signals assigned to the $-\mathrm{NCH}_{2}$ proton, o- $\mathrm{CH}_{3}$ group and $\mathrm{C}_{5} \mathrm{H}_{4} \mathrm{C}\left(\mathrm{CH}_{3}\right)_{2}$ group (blue bottom line); (b) the same sample after addition of $\mathrm{ca}$. an equimolar amount of 5 (brown top line).
W. B., Ł. B. and P. B. would like to thank the National Science Centre for financial support (grant DEC-2011/01/B/ ST5/06297).

\section{Notes and references}

1 C. G. Newton, D. Kossler and N. Cramer, J. Am. Chem. Soc., 2016, 138, 3935, and references therein.

2 C. D. Abernethy, A. H. Cowley and R. A. Jones, J. Organomet. Chem., 2000, 596, 3.

3 Selected references: (a) R. A. Kelly III, N. M. Scott, S. DíezGonzález, E. D. Stevens and S. P. Nolan, Organometallics, 2005, 24, 3442; (b) W. Buchowicz, A. Kozioł, L. B. Jerzykiewicz, T. Lis, S. Pasynkiewicz, A. Pęcherzewska and A. Pietrzykowski, J. Mol. Catal. A: Chem., 2006, 257, 118; (c) D. A. Malyshev, N. M. Scott, N. Marion, E. D. Stevens, V. P. Ananikov, I. P. Beletskaya and S. P. Nolan, Organometallics, 2006, 25, 4462; (d) V. Ritleng, A. M. Oertel and M. J. Chetcuti, Dalton Trans., 2010, 39, 8153; (e) W. Buchowicz, W. Wojtczak, A. Pietrzykowski, A. Lupa, L. B. Jerzykiewicz, A. Makal and K. Woźniak, Eur. J. Inorg. Chem., 2010, 648; (f) A. M. Oertel, V. Ritleng and M. J. Chetcuti, Organometallics, 2012, 31, 2829; $(g)$ L. P. Bheeter, M. Henrion, L. Brelot, C. Darcel, M. J. Chetcuti, J.-B. Sortais and V. Ritleng, Adv. Synth. Catal., 2012, 354, 2619; (h) A. R. Martin, Y. Makida, S. Meiries, A. M. Z. Slawin and S. P. Nolan, Organometallics, 2013, 32, 6265; ( $i$ ) Ł. Banach, P. A. Guńka, D. Górska, M. Podlewska, J. Zachara and W. Buchowicz, Eur. J. Inorg. Chem., 2015, 5677; (j) A. Włodarska, A. Kozioł, M. Dranka, J. Jurkowski and A. Pietrzykowski, J. Mol. Catal. A: Chem., 2014, 395, 481; (k) Ł. Banach, P. A. Guńka and W. Buchowicz, Dalton Trans., 2016, 45, 8688.

4 Selected references: $(a)$ C. Radloff, F. E. Hahn, T. Pape and R. Fröhlich, Dalton Trans., 2009, 7215; (b) A. M. Oertel, J. Freudenreich, J. Gein, V. Ritleng, L. F. Veiros and M. J. Chetcuti, Organometallics, 2011, 30, 3400; (c) A. M. Oertel, V. Ritleng, L. Burr and M. J. Chetcuti, Organometallics, 2011, 30, 6685; (d) W. Buchowicz, Ł. Banach, J. Conder, P. A. Guńka, D. Kubicki and P. Buchalski, Dalton Trans., 2014, 43, 5847; (e) S. Pelties, D. Herrmann, B. de Bruin, F. Hartl and R. Wolf, Chem. Commun., 2014, 50, 7014.

5 (a) S. P. Downing and A. A. Danopoulos, Organometallics, 2006, 25, 1337; (b) A. P. da Costa, M. Viciano, M. Sanaŭ, S. Merino, J. Tejeda, E. Persi and B. Royo, Organometallics, 2008, 27, 1305; (c) V. V. K. M. Kandepi, J. M. S. Cardoso, E. Peris and B. Royo, Organometallics, 2010, 29, 2777; (d) J. M. S. Cardoso and B. Royo, Chem. Commun., 2012, 48, 4944; (e) B. Royo and E. Peris, Eur. J. Inorg. Chem., 2012, 1309; $(f)$ B. Royo, in Advances in Organometallic Chemistry and Catalysis: The Silver/Gold Jubilee International Conference on Organometallic Chemistry Celebratory Book, ed. A. J. L. Pombeiro, J. Wiley \& Sons, 2014, vol. 10, pp. 133-143. 
6 H.-M. Sun, D.-M. Hu, Y.-S. Wang, Q. Shen and Y. Zhang, J. Organomet. Chem., 2007, 692, 903.

7 (a) L. Postigo and B. Royo, Adv. Synth. Catal., 2012, 354, 2613; (b) L. Postigo, R. Lopes and B. Royo, Dalton Trans., 2014, 43, 853.

8 (a) E. B. Bauer and J. A. Gladysz, in Handbook of Metathesis, ed. R. H. Grubbs, Wiley-VCH, Weinheim, Germany, 2003, vol. 2, 2.11, pp. 403-431; (b) A. Pietrzykowski and W. Buchowicz, in Advances in Organometallic Chemistry and Catalysis: The Silver/Gold Jubilee International Conference on Organometallic Chemistry Celebratory Book, ed. A. J. L. Pombeiro, J. Wiley \& Sons, 2014, vol. 12, pp. 157-170; (c) T. Fiedler and J. A. Gladysz, in Olefin Metathesis: Theory and Practice, ed. K. Grela, John Wiley \& Sons, 2014, vol. 9, pp. 311-328.

9 Selected references: (a) M. Ogasawara, W. Y. Wu, S. Arae, K. Nakajima and T. Takahashi, Organometallics, 2013, 32, 6593; (b) Y.-Y. Tseng, K. Kamikawa, Q. Wu, T. Takahashi and M. Ogasawara, Adv. Synth. Catal., 2015, 357, 2255; (c) R. E. Andrew and A. B. Chaplin, Inorg. Chem., 2015, 54, 312; (d) A. L. Estrada, T. Jia, N. Bhuvanesh, J. Blümel and J. A. Gladysz, Eur. J. Inorg. Chem., 2015, 5318; (e) G. M. Lang, T. Shima, L. Wang, K. J. Cluff, K. Skopek, F. Hampel, J. Blümel and J. A. Gladysz, J. Am. Chem. Soc., 2016, 138, 7649.
10 M. Scholl, S. Ding, C. W. Lee and R. H. Grubbs, Org. Lett., 1999, 1, 953.

$11\left[\mathrm{Ru}(=\mathrm{CHPh}) \mathrm{Cl}_{2}\left(\mathrm{PCy}_{3}\right)_{2}\right]$ also did not afford efficient RCM in complex 1. Some related $\alpha, \omega$-diene complexes, e.g. $\left[\mathrm{Ni}\left(\mathrm{C}_{5} \mathrm{H}_{4} \quad \mathrm{CH}_{2} \mathrm{CH}=\mathrm{CH}_{2}\right)(\mathrm{Br})(\right.$ allyl-IMes $\left.)\right], \quad\left[\mathrm{Ni}\left(\mathrm{C}_{5} \mathrm{H}_{4}\right.\right.$ $\left.\mathrm{CH}_{2} \mathrm{CH}=\mathrm{CH}_{2}\right)(\mathrm{Cl})($ allyl-IMes) $], \quad\left[\mathrm{Ni}\left(\mathrm{C}_{5} \mathrm{H}_{4}\left(\mathrm{CH}_{2}\right)_{2} \mathrm{CH}=\mathrm{CH}_{2}\right)\right.$ $\left.(\mathrm{Br})\left(\mathrm{CH}_{2}=\mathrm{CH}\left(\mathrm{CH}_{2}\right)_{2} \mathrm{IMes}\right)\right]$ (see Fig. S3 $\dagger$ ) did not undergo RCM under conditions similar to those for 2 .

12 According to integration of doublets of the imidazole protons at $\delta 6.32 \mathrm{ppm}(J=1.9 \mathrm{~Hz}, E)$ and $\delta 6.30 \mathrm{ppm}(J=$ $1.9 \mathrm{~Hz}, Z)$.

13 A similar trend was observed for diansa-metallocenes: W. Buchowicz, A. Furmańczyk, J. Zachara and M. Majchrzak, Dalton Trans., 2014, 41, 9296-9271.

14 S. Braun, H.-O. Kalinowski and S. Berger, 100 and More Basic NMR Experiments: A Practical Course, VCH, Weinheim, 1996.

15 As noted by the referee, taking into account the chirality and $E / Z$ isomers of the $\mathrm{C}=\mathrm{C}$ bond, four stereoisomers of 4 are formed in this reaction $(\Delta, Z ; \Delta, E ; \Lambda, Z ; \Lambda, E)$. Doubling of signals for the $Z$ isomers in the presence of $\mathbf{5}$ was clearly observed for the $\mathrm{NCH}_{2}-$ signal (see Fig. S4 $\dagger$ ). Preliminary attempts to hydrogenate the $\mathrm{C}=\mathrm{C}$ bond in $4\left(\mathrm{H}_{2} / \mathrm{PtO}_{2}\right.$, toluene, room temp., $48 \mathrm{~h}$ ) resulted in incomplete conversion of 4 . 